\title{
Risk Factors and Clinical Profile of Respiratory Distress in Newborn: A Hospital Based Study in Bangladesh Army
}

\author{
${ }^{*}$ Raha $\mathrm{BK}^{1}$, Alam MJ ${ }^{2}$, Bhuiyan $\mathrm{MAQ}^{3}$
}

\begin{abstract}
Neonatal respiratory distress (NRD) is a main cause of neonatal morbidity and mortality in developing countries. Early detection of its risk factors and early treatment of its causes are major challenges. There are many causes of respiratory distress, among them, transient tachypnea of newborn (TTN), respiratory distress syndrome (RDS) and perinatal asphyxia are commonest causes. Timely and appropriate therapy is essential to prevent ongoing injury and improve outcome. The aim of this study was to determine the risk factors and to identify the causes of respiratory distress in neonatal intensive care unit (NICU) in Combined Military hospital (CMH) Sylhet and to observe the hospital outcome of these babies. Descriptive type of cross- sectional study was conducted in CMH Sylhet over a period of one year from April 2018 to March 2019. During the study period a total of 287 live newborns were found and included as study subjects to observe for development of respiratory distress. The overall prevalence of respiratory distress was $19.2 \%$. There was male predominance (63.6\%) and more than two third (71.1\%) were born by cesarean section. Prematurity (38.2\%), low birth weight (52.7\%), male gender (63.6\%), APGAR at 1 min $<7(10.9 \%)$, caesarean delivery $(76.4 \%)$, less antenatal care visit (52.7\%), more than 4 pervaginal examinations $49.1 \%$, acute fetal distress $43.6 \%$ and gestational diabetes mellitus $34.5 \%$ were the most common risk factors for development of NRD. The main causes were transient
\end{abstract}

1. *Dr. (Lt Col) Biplob Kumar Raha, Classified Specialist in Paediatrics, Combined Military Hospital Sylhet, Jalalabad Cantonment. Mobile: 01716942580, E-mail: biplob101584@gmail.com

2. Col (Dr.) Md Julfikkar Alam, Commandant, Combined Military Hospital Sylhet, Jalalabad Cantonment.

3. Col (Dr.) Md Abdul Quddus Bhuiyan, Classified Spl in Medicine \& Nephrology, Combined Military Hospital Sylhet, Jalalabad Cantonment.

* For correspondence tachypnea of newborn $47.3 \%$, respiratory distress syndrome $29.1 \%$ and perinatal asphyxia 10.9\%. All babies required high flow oxygen initially, subsequently Bubble Continuous Positive Airway Pressure (CPAP) and mechanical ventilation was required in $14.5 \%$ and $1(1.8 \%)$ cases respectively. Mortality was $1.8 \%$ in neonates with respiratory distress syndrome with pneumothorax with septicaemia requiring mechanical ventilation. NRD is a frequent emergency and causes high morbidity and mortality. Risk factors like prematurity, low birth weight, male gender, APGAR at 1 min $<7$, caesarean delivery, less antenatal care visit, more than 4 pervaginal examinations, acute fetal distress and gestational diabetes mellitus were associated with respiratory distress in newborns. Majority of cases are due to TTN followed by respiratory distress syndrome and perinatal asphyxia. Mortality was in RDS mainly related to pneumothorax with septicaemia. Better obstetrical care and timely intervention may improve the outcome of newborn respiratory distress.

Keywords: Meconium aspiration syndrome (MAS), respiratory distress $(R D)$, respiratory distress syndrome (RDS), transient tachypnea of the newborn (TTN)

\section{INTRODUCTION}

Respiratory disorders are the most frequent cause of admission for neonatal intensive care in both term and preterm infants. ${ }^{1}$ Fifteen percent of term infants and 29\% of late preterm infants admitted to the neonatal intensive care unit develop significant respiratory morbidity; this is even higher for infants born before 34 weeks gestation. ${ }^{2}$ It occurs in 0.96 to $12 \%$ of live births and is responsible for about $20 \%$ of neonatal mortality. ${ }^{3}$ The severity of respiratory distress can be assessed by Downe's scoring system which includes parameters such as respiratory rate, cyanosis, retractions, grunting and air entry in both the lungs. ${ }^{4}$

The risk factors include prematurity, male gender, asphyxia, caesarean delivery, maternal diabetes mellitus, and hypertensive disorders of pregnancy, antepartum 
hemorrhage, multiple pregnancies, and rapid labor. ${ }^{5,6}$ The causes of respiratory distress in neonates include transient tachypnea of newborn (TTN), respiratory distress syndrome (RDS), meconium aspiration syndrome (MAS), congenital pneumonia, congenital heart disease (CHD), perinatal asphyxia (PNA), and congenital anomalies as tracheo-oesophageal fistula, and congenital diaphragmatic hernia. $^{7}$

Early detection of its risk factors and anticipation of the management of its etiologies are imperative. ${ }^{8}$ There has been a tremendous advance in the management of respiratory distress such as ventilator therapy with different modes such as Continuous Positive Airway Pressure (CPAP), conventional mechanical ventilation; ultra high frequency jet ventilation, liquid ventilation, surfactant replacement therapy, sophisticated monitoring and extracorporeal membrane oxygenation all have improved the outcome among the babies with respiratory distress. ${ }^{9}$

In spite of the varying recent advance in clinching diagnosis and management there have been very less clinical studies on the neonatal respiratory distress in our country. So, the aim of the study was to find out the risk factors and causes of respiratory distress among the admitted newborns in neonatal intensive care unit (NICU) in $\mathrm{CMH}$ Sylhet and to observe the hospital outcome of these babies.

\section{MATERIAL AND METHODS}

This descriptive type of cross-sectional study was carried out at NICU, CMH Sylhet during April 2018 to March 2019. Any newborn showing one or more of the following signs (for $>2$ hours) was considered to have respiratory distress which includes parameters such as tachypnea or respiratory rate of more than $60 /$ minute, retraction or increased chest in-drawing on respirations (subcostal, intercostal, sternal, and suprasternal) and noisy respiration in the form of grunt, stridor or wheeze were included in this study and babies with multiple congenital malformations were excluded. The ethical approval of the study was obtained from ethical review committee of the area headquarter, Sylhet cantonment, Sylhet. Diagnosis was done within 24 hours of admission according to their clinical presentation and relevant investigations. Inform consent was taken from each patient before enrollment. Data were collected by checkup sheet and appropriate questionnaire who were admitted in NICU.

After the initial assessment and cardio respiratory management, a history was obtained. Maternal and obstetrical histories were taken which provided invaluable information. Intra-partum details with special reference to the fetal well-being, maternal age, antenatal care visits, pervaginal examinations, duration of rupture of membranes, quantity and quality of liquor, gestational diabetes mellitus, drugs especially analgesics and sedatives given to the mother were recorded. Apgar score, resuscitation details, sex, and gestational age was assessed by modified Ballard score and clinical examination, birth weight and findings suggestive of respiratory distress were also noted. Data regarding use of mechanical ventilation, Bubble CPAP or required only oxygen were recorded. Statistical analysis was performed using the commercial statistical software Epi info version 3.5.

\section{RESULTS}

The total number of live births during the study period was 287. Total number of caesarean section deliveries were 204 $(71.1 \%)$ and spontaneous vaginal deliveries were 83 (28.9\%). Out of all these cases 55 (19.2\%) newborns developed respiratory distress. Among respiratory distress male was $35(63.6 \%)$ and female was 20 (36.4\%). Full term newborns were $31(56.4 \%)$, premature newborns were $21(38.2 \%)$, and post term was $3(5.4 \%)$. The overall prevalence of respiratory distress was $19.2 \%$. Mean gestational age was $35.6 \pm 3.1 \mathrm{wks}$ (range - 31 to 41 weeks). Mean weight was $2447 \pm 826 \mathrm{gm}$ (range -1400 to 4100 gm). Fifty two (52\%) babies had normal birth weight, 28 $(50.9 \%)$ were low birth weight, $1(1.8 \%)$ were very low birth weight and $1(1.8 \%$ ) were macrosomic (weight $>4000 \mathrm{gm}$ ) babies. The risk factors associated with neonatal respiratory distress are shown in (Table 1).

Table 1 shows neonatal risk factors include prematurity (38.2\%), male gender (63.6\%), Low birth weight $<2500$ gm) (52.7\%), meconium stained liquor (21.8\%), APGAR at $1 \mathrm{~min}<7(10.9 \%)$ and maternal risk factors include caesarean delivery $(76.4 \%)$, attending less than three antenatal visits $(52.7 \%)$, more than four pervaginal examinations (49.1\%), fetal distress (43.6\%), gestational diabetes mellitus (34.5\%) and advanced maternal age $>35$ years $(25.5 \%)$ were the most common risk factors for development of NRD. 
Table I: Risk factors associated with neonatal respiratory distress $(n=55)$

\begin{tabular}{|l|c|c|}
\hline Risk factors & Number & Percentage \\
\hline & of factors & $(\%)$ \\
\hline Neonatal factors & 21 & $38.2 \%$ \\
\hline Prematurity & 35 & $63.6 \%$ \\
\hline Male baby & 29 & $52.7 \%$ \\
\hline Low birth weight <2500 gm) & 12 & $21.8 \%$ \\
\hline Meconium stained liquor & 06 & $10.9 \%$ \\
\hline APGAR at 1 min < & 06 & $10.9 \%$ \\
\hline Knotting of the cord & 03 & $5.4 \%$ \\
\hline Post maturity & 42 & $76.4 \%$ \\
\hline Obstetrical factors & 29 & $52.7 \%$ \\
\hline Cesarean section & 27 & $49.1 \%$ \\
\hline Number of antenatal care visits $<3$ & 24 & $43.6 \%$ \\
\hline$>4$ pervaginal examinations & 19 & $34.5 \%$ \\
\hline Fetal distress & 14 & $25.5 \%$ \\
\hline Gestational diabetes mellitus & 12 & $21.8 \%$ \\
\hline Advanced maternal age $>35$ years & 11 & $20.0 \%$ \\
\hline Oligohydramnios & 10 & $18.2 \%$ \\
\hline Pregnancy induced hypertension & 09 & $16.4 \%$ \\
\hline $\begin{array}{l}\text { Prolonged rupture of membrane } \\
>12 \text { hours }\end{array}$ & 07 & $12.7 \%$ \\
\hline $\begin{array}{l}\text { Maternal fever at the time of } \\
\text { delivery > 38 }\end{array}$ & 04 & $7.3 \%$ \\
\hline $\begin{array}{l}\text { Bad obstetrical history } \\
\text { (abortion, still birth) }\end{array}$ & \\
\hline Prolonged labor & $14.5 \%$ \\
\hline Twin pregnancy & & \\
\hline
\end{tabular}

Table 2 shows TTN was found to be the commonest cause of respiratory distress (47.3\%) and it was found to be the commonest cause of respiratory distress among both term and preterm babies. RDS was the second commonest cause of respiratory distress $(29.1 \%)$ and it was found in preterm babies. PNA was the third commonest cause of respiratory distress (10.9\%) and it was found in term and post term newborns. Congenital pneumonia, CHD, septicaemia, and MAS were found in $3.6 \%, 3.6 \%, 3.6 \%$, and $1.8 \%$ of cases respectively.

\section{Table-II : Causes of respiratory distress of studied newborn $(n=55)$}

\begin{tabular}{|l|c|c|}
\hline Disease & Number & Percentage \\
\hline $\begin{array}{l}\text { Transient tachypnea of newborn } \\
\text { (TTN) }\end{array}$ & 26 & $47.3 \%$ \\
\hline Respiratory distress syndrome (RDS) & 16 & $29.1 \%$ \\
\hline Perinatal asphyxia (PNA) & 6 & $10.9 \%$ \\
\hline Congenital pneumonia & 2 & $3.6 \%$ \\
\hline Congenital heart disease (CHD) & 2 & $3.6 \%$ \\
\hline Septicaemia & 2 & $3.6 \%$ \\
\hline $\begin{array}{l}\text { Meconium aspiration syndrome } \\
\text { (MAS) }\end{array}$ & 1 & $1.8 \%$ \\
\hline
\end{tabular}

Table III shows causes of respiratory distress with obstetrics and gestational history are shown in

Table III : Causes of respiratory distress with obstetrics and gestational history

\begin{tabular}{|l|c|c|c|c|c|c|c|}
\hline Criteria & TTN & RDS & PNA & $\begin{array}{c}\text { Congenital } \\
\text { pneumonia }\end{array}$ & CHD & Septicaemia & MAS \\
\hline M:F & $1.4: 1$ & $1.3: 1$ & $2: 1$ & $1: 1$ & $1: 1$ & $1: 1$ & $1: 1$ \\
\hline Term (\%) & $88.5 \%$ & $6.3 \%$ & $66.7 \%$ & $50 \%$ & $50 \%$ & $0 \%$ & $100 \%$ \\
\hline Preterm (\%) & $11.5 \%$ & $93.7 \%$ & $33.3 \%$ & $50 \%$ & $50 \%$ & $100 \%$ & $0 \%$ \\
\hline Mean GA & 37.1 & 32.5 & 37.3 & 37.1 & 36.2 & 34.5 & 41 \\
(weeks) \pm SD & $( \pm 1.1)$ & $( \pm 0.8)$ & $( \pm 1.2)$ & $( \pm 1.0)$ & $( \pm 1.1)$ & $( \pm 1.1)$ & $( \pm 1.2)$ \\
\hline Mean weight & 2900 & 1500 & 2700 & 2740 & 2500 & 1850 & 3100 \\
(grams) \pm SD & $( \pm 880)$ & $( \pm 770)$ & $( \pm 565)$ & $( \pm 630)$ & $( \pm 820)$ & $( \pm 785)$ & $( \pm 740)$ \\
\hline C/S & $69.2 \%$ & $87.5 \%$ & $83.3 \%$ & $100 \%$ & $100 \%$ & $50 \%$ & $100 \%$ \\
\hline NVD & $30.8 \%$ & $12.5 \%$ & $16.7 \%$ & $0 \%$ & $0 \%$ & $50 \%$ & $0 \%$ \\
\hline
\end{tabular}


Table IV shows all babies required high flow oxygen initially by head box 55 (100\%), subsequently Bubble CPAP and mechanical ventilation was required in 8 $(14.5 \%)$ and $1(1.8 \%)$ cases respectively.

Table IV: Treatment of patients of respiratory distress

\begin{tabular}{|l|c|}
\hline High flow oxygen through head box & $55(100 \%)$ \\
\hline Bubble CPAP & $8(14.5 \%)$ \\
\hline Mechanical ventilation & $1(1.8 \%)$ \\
\hline
\end{tabular}

Mortality was $1.8 \%$ in neonates with respiratory distress syndrome with pneumothorax with septicemia requiring mechanical ventilation.

\section{DISCUSSION}

Respiratory distress, the most common cause for which baby needed intensive care support and death rate was 2-4 times more in this group of patients than those required admission without respiratory distress. ${ }^{10}$ The overall prevalence of respiratory distress in this study was $19.2 \%$. Results from our study are comparable with results from developed countries with reported prevalence rates of $4.24 \%$ in Pakistan. ${ }^{11} 18.5 \%$ in France ${ }^{12}, 23 \%$ in Ivory Coast ${ }^{13}$ and $14.5 \%$ Burkina Faso. ${ }^{14}$

In the present study, neonatal risk factors include prematurity $(38.2 \%)$, male gender (63.6\%), Low birth weight $<2500 \mathrm{gm})(52.7 \%)$, meconium stained liquor (21.8\%), APGAR at $1 \mathrm{~min}<7(10.9 \%)$ and maternal risk factors include caesarean delivery $(76.4 \%)$, attending less than three antenatal visits $(52.7 \%)$, more than four pervaginal examinations (49.1\%), fetal distress (43.6\%), gestational diabetes mellitus (34.5\%) and advanced maternal age $>35$ years $(25.5 \%)$ were the most common risk factors for development of NRD (Table 1).

Low gestational age at the time of delivery was a risk factor for respiratory distress also observed by Dani $\mathrm{C}$ et al, and Lureti $\mathrm{M}$ et al. ${ }^{15},{ }^{16}$ Lureti $\mathrm{M}$ et al, and Miller HC shows the frequency of neonatal respiratory distress was higher in males than compared with females. ${ }^{16,17}$ The studies conducted by Dani C et al, Lureti M et al, Miller HC et al and Lee $\mathrm{K}$ et al, also mentioned that low birth weight is a risk factor for respiratory distress among newborn baby ${ }^{15-18}$. The studies conducted by Rygal $\mathrm{M},{ }^{19}$ where meconium stained liquor had more chances of developing respiratory distress. Lureti $\mathrm{M}$ et al, Fidanovski $\mathrm{D}$ et al and Gouyon $\mathrm{J}$ et al observed that low APGAR score were associated with increased RD and prolonged NICU stay. ${ }^{16}$, 20, 21
The studies conducted by Dani C, Gouyon J, Geller EJ where it was noticed that caesarian delivered babies have more chances of neonatal respiratory distress when compared to normal vaginal delivery. ${ }^{15,21,22}$ Dani C et al has shown that the number of PV examination above 4 was significantly associated with respiratory distress. ${ }^{15}$ Advanced maternal age responsible for newborn respiratory distress also reported by Dani $\mathrm{C}$ et al and Smith A et al respectively. ${ }^{15,23}$

In the present study, the most common causes of respiratory distress found were TTN (47.3\%), RDS (29.1\%), PNA (10.9\%), septicemia (3.6\%), congenital pneumonia $(3.6 \%)$ and congenital heart disease $(3.6 \%)$ (Table II). Santosh $\mathrm{S}^{24}$ et al also reported near similar finding.

TTN was the commonest (47.3\%) cause of respiratory distress in this study. In many study, TTN was found to be the commonest cause which was consistent with this study ${ }^{25}, 26$ Among the neonates with TTN 88.5\% were term and their mean Gestational age was 37.1 weeks, and their mean weight was $2900 \mathrm{gm}$. Two third (69.2\%) were delivered by C/S. Different studies showed cesarean section, term babies and male predominance to be associated with TTN. ${ }^{27,28}$ In this study similar result was found but more than half of the TTN cases were term baby but their birth weight was normal. Assisted ventilation in the form of bubble CPAP (bCPAP) was required in 14.5\% cases without any mortality. Zaazou $\mathrm{MH}$ et al. found $37.9 \%$ neonates had respiratory distress due to TTN among them $11.5 \%$ cases required nasal CPAP with no mortality. ${ }^{27}$ Many other studies also reported cases with TTN requiring assisted ventilation without any mortality. 26,29

RDS is an important cause of respiratory distress in our set up and also was the second common cause in our study. It constituted 29.1\% of cases. Majority (93.7\%) were preterm with mean gestational age 32.5 weeks and mean weight of 1500 gram. One study showed that RDS was the second commonest cause of respiratory distress which constituted $31 \%$, like our finding ${ }^{27}$. In many other studies showed low percentage (2-7\%) of RDS. ${ }^{26}, 30,31$ Assisted ventilation was required for the management of RDS, in the form of bCPAP and mechanical ventilation in 14.5\% and $1.8 \%$ cases respectively. Mortality was $1.8 \%$ among the ventilated baby who required mechanical ventilation associated with pneumothorax with septicemia while no death observed who required bCPAP. One study showed 
that $83.2 \%$ cases of RDS required ventilator support and mortality rate was $76.0 \%$ who put on IMV mode. ${ }^{26}$

Perinatal asphyxia still remains one of the major cause of neonatal respiratory distress. ${ }^{32,} 33$ Perinatal asphyxia was the third common (10.6\%) cause of respiratory distress in this study. Their mean gestational age 37.3 weeks and mean weight 2600 grams. Nessa L et al found 52\% newborn had respiratory distress who had perinatal asphyxia ${ }^{30}$ which is much higher than our study but on the contrary, many other study showed low incidence of perinatal asphyxia. ${ }^{26,27}$

In this study, among all cases with respiratory distress, mechanical ventilation was required in $1.8 \%$ cases and bCPAP required in $14.5 \%$ cases. There was no death who required bCPAP but mortality rate was $1.8 \%$ among the babies who required mechanical ventilation. One study reported that mortality was high $(80 \%)$ in perinatal asphyxia who required mechanical ventilation. ${ }^{27}$ Lawn et al. reported that mortality rate in cases of perinatal asphyxia is as high as $25-50 \% .^{34}$

Neonatal sepsis is an important and common cause of neonatal morbidity and mortality. ${ }^{35-37}$ We found septicemia as the fourth (3.6\%) cause of respiratory distress in this study. Majority (100\%) of them were preterm, mean gestational age was 34.5 weeks and mean weight was 1850 grams. Mechanical ventilation and bCPAP were required in $1.8 \%$ and $14.5 \%$ cases respectively among these babies. Among these babies, 1 (1.8\%) died who required mechanical ventilation but no death was observed who required bCPAP. One study reported that case fatality rate is $33.3 \%$ in the cases with neonatal sepsis. ${ }^{30}$

Congenital pneumonia was found in $3.6 \%$ cases. $50 \%$ were preterm mean gestational age was 37.1 weeks. Dutta A et al found pneumonia as the second common cause of respiratory distress in his study, ${ }^{26}$ where in most cases it was part of septicemia and $34.28 \%$ was primary pneumonia. In another study, pneumonia was found to be a cause of respiratory distress in $8 \%$ cases, ${ }^{30}$ which is near to our finding. Mechanical ventilation and bCPAP were required in $1.8 \%$ and $14.5 \%$ cases respectively among these babies. No death was observed in cases required bCPAP or mechanical ventilation.

\section{CONCLUSIONS}

Neonatal respiratory distress is a major cause of neonatal admissions and has a high mortality rate. Risk factors like prematurity, low birth weight, male sex, meconium stained liquor, $\mathrm{APGAR}$ at $1 \mathrm{~min}<7$, attending less than three antenatal visits, more than 4 per vaginal examinations, fetal distress and cesarean delivered newborns were associated with severe respiratory distress in newborns. Most common causes of respiratory distress are TTN, RDS, perinatal asphyxia and septicemia. Better obstetrical care and awareness of the risk factors of birth asphyxia among mothers and fetus, along with adequate follow-up of pregnancy and labor for early detection of risk factors and timely intervention may improve the outcome of neonatal respiratory distress.

\section{REFERENCES}

1. Carlo WA, Ambalavanan N. Respiratory Distress Syndrom. In: Kliegman RM, Stanton BMD, St. Geme J, Schor NF, editors. Nelson Textbook of Pediatrics. 20th edition. Elsevier: 2016; 20(1): 579-80.

2. Hibbard JU, Wilkins I, Sun L, Gregory K, Haberman S. Respiratory morbidity in late preterm births. JAMA. 2010; 304(4): 419-25.

3. Kommawar A, Borkar R,Vagha J, Lakhkar B, Meshram R, Taksandae A. Study of respiratory distress in newborn. Int J Contemp Pediatr. 2017; 4(2): 490-94.

4. Singh M. Care of the newborn. Revised 8th ed. CBS Publishers and Distributors Pvt Ltd; September 2016: 350-54.

5. Lorotte-Namoumi C, Clamadieu, Jarreau PH. Détresses respiratoires du nouveau-né en dehors des malformations et des maladies génétiques ou constitutionnelles. Encycl Med Chir (Elsevier Paris) Pédiatrie. 2004; 4:10-1.

6. Chalacon M, Debillon T, Plantaz D, Ego A. Facteurs de risque détresse respiratoire chez les prématurés modérés (32 a 34 semaines d'aménorrhées). Thèse. Université Joseph Fourrier. 2012. Google Scholar

7. Am Fam. Physician American Academy of Family Physicians. 2007; 76: 987-94.

8. Fedakar A, Aydogdu C. Clinical features of neonates treated in the intensive care unit for respiratory distress. Turk J Pediatr. 2011; 53(2):173-79.

9. Rao GC, Rao MSP. Etiological profile of respiratory distress in first day of life of a newborn baby. Int J Contemp pediatr. 2017; 4(1): 210-14. 
10. Misra PK. Respiratory distress in newborn. Indian Pediatrics. 1987; 24: 77-80.

11. Saeed Z, Lutufullah G, Hassan R. Prevalence and Etiology of Respiratory Distress in newborns. PAFMJ. 2013; 63(1): 22-25.

12. Chalacon M, Debillon T, Plantaz D, Ego A. Facteurs de risque détresse respiratoire chez les prématurés modérés (32 a 34 semaines d'aménorrhées). Thèse. Université Joseph Fourrier. 2012.

13. Lasme E, Amon TD, Akaffou E, Ehua-Amangoua E, Koffi O, Kangah D. Les facteurs de risque des détresses respiratoires néonatales en milieu hospitalier a Abidjan. Ann Pediatr (Paris). 1997; 44(9): 635-39.

14. Kam KI, Ye D, Sawadogo A, Sanou I, Traore A, Koueta $\mathrm{F}$ et al. Les Détresses Respiratoires du nouveau-né dans L'unité de Néonatologie du centre hospitalier National de Ouagadougou, Burkina Faso. Burkina Médical. 1998; 2: 447.

15. Dani C, Reali MF, Bertini G. Risk factors for the development of respiratory distress syndrome and transient tachypnoea in newborn infants. European Respiratory J. 1999; 14:155-59.

16. Lureti M. Risk factors for respiratory distress syndrome in newborn infants: A multi centre Italian survey. Acta Obstetr Gynecol Scandinavica. 1993; 72: 359-64.

17. Miller HC. Respiratory Distress Syndrome of Newborn Infants: Statistical Evaluation of Factors Possibly Affecting Survival of Premature Infants. Pediatr.1998; 31 (4): 573-79.

18. Kwang-sun Lee, Arthur I Eidelman, Po-I Tseng, Stephen R. Kandail, Lawrence M: Respiratory Distress Syndrome of the Newborn and Complications of Pregnancy. Pediatrics. 1976; 58: 675-80.

19. Rygal M. Neonatal respiratory distress syndrome: anautopsy study of 190 cases. Indian J Pediatr. 1985; 52: 43-46.

20. Fidanovski D, Milev V, Sajkovski A. Mortality risk factors in premature infants with respiratory distress syndrome treated with mechanical ventilation. Srp Arh Celok Lek. 2005; 133: 29-35.
21. Gouyon J, Ribakovsky C, Ferdyns C. Severe respiratory distress in term neonates. Pediatr Perinatal Epidemiol. 2001; 22: 22-30.

22. Geller EJ, Wu JM, Jannelli ML, Nguyen TV. Neonatal outcomes associated with planned vaginal versus planned primary cesarean delivery. Journal of Perinatology. 2010; 30: 258-64.

23. Smith A, Malhotra A. Respiratory distress in newborn treated with ventilation. Indian J Pediatr. 1995; 3: 207-11.

24. Santosh S, Kumar K, Adarsha E. A clinical study of respiratory distress in newborn and its outcome. Indian J Neonatal Med Res. 2013; 1: 2-4.

25. Kumar A, Bhat V.B. Epidemiology of respiratory distress of newborns. Indian Journal Pediatrics. 1996; 63(1): 93-98.

26. Dutta A, Sinhamahapatra KT. Spectrum of respiratory distress in newborn: A study from a tertiary care hospital in Kolkata. The Child and newborn. 2011; 15(2): 45- 48.

27. Zaazou MH, Kamal MM, Ali R M, Hussieny NE, Sayed ME. Descriptive study of cases of respiratory distress in NICU in Ahmed Maher Teaching hospital. Medical Journal Cairo University. 2011; 79(1): 44148.

28. Rawlings JS and Smith FR. Transient tachypnea of the newborn: An analysis of neonatal and obstetric risk factors. American Journal of Diseases of Children. 1984; 138 (9): 869-71.

29. Helve O, Andresson S, Kirjavainen T, Pitkanen OM. Improvement of lung compliance during post natal adaptation correlates with airway sodium transport. American Journal of Respiratory and Critical Care Medicine. 2006; 173: 448-52.

30. Nessa L, Khatun S, Banu NA, Rouf A, Khan MSR, Haque $\mathrm{N}$ et al. Etiology and outcome of respiratory distress in newborn. Chest \& Heart Journal. 2011; 35 (1): $1-4$.

31. Banu K, Rahman MS. Disease in the neonatal period: A study in the special care baby unit of Dhaka Shishu Hospital. Bang J Child Health. 1982; 6(3): 133- 39. 
32. Mishra PK, Srivastava N, Malik GK, Kapoor RK, Srivastava KL, Tastogi S. Outcome in relation to APGAR score in term neonates. Indian J Pediatrics. 1994; 3:1215-18.

33. Suresh GM, Sarker S. Delivery room management of infants born through thin Meconium stained liquor. Indian J Pediatrics. 1994; 31: 1177-81.

34. Lawn J, Shibuya K and Stein C. No cry at birth: Global estimates of intrapartum stillbirths and antrapartum related neonatal deaths. Bull. World Health Organ June. 2005; 83 (6): 409-17.

35. Jamal M, Khan N. Neonatal Morbidity and Mortality in high risk pregnancies. JCPSP. 2002; 12(11): 657-61.

36. Aurangzeb B, Hameed A. Neonatal sepsis in hospital borne-babies; bacterial isolates and antibiotic susceptibility patterns. JCPSP. 2003; 13(11): 629- 32.

37. Report of the National Neonatal Perinatal Database (National Neonatology Forum), India 2002-03. 